Revista do SELL

v. 6 , no. 3

ISSN: $1983-3873$

\title{
A ABORDAGEM DOS GÊNEROS DISCURSIVOS EM UM LIVRO DIDÁTICO DE PORTUGUÊS: LIAMES ENTRE TEORIA E PRÁTICA
}

\author{
THE DISCURSIVE GENRES APPROACH IN A PORTUGUESE TEXTBOOK: THE TIES \\ BETWEEN THEORY AND PRACTICE
}

\author{
Graciethe da Silva de Souza \\ Universidade Estadual do Sudoeste da Bahia \\ Márcia Helena de Melo Pereira \\ Universidade Estadual do Sudoeste da Bahia
}

\begin{abstract}
RESUMO: Tornou-se consenso entre linguistas e professores, após discussões acirradas em torno do fracasso escolar quanto ao ensino da disciplina de Língua Portuguesa, que a unidade básica de ensino deve ser o texto. Sendo assim, os diversos gêneros discursivos, orais ou escritos, que organizam e concretizam o nosso dizer, devem dar ao texto uma funcionalidade, uma vez que toda manifestação linguística que produzimos é feita por meio de um gênero. Nessa direção, é preciso priorizar uma transposição didática de gêneros que favoreça o desenvolvimento da competência sócio-discursiva do aprendiz, tornando-o capaz de atuar linguisticamente nas mais diversas situações comunicativas. Objetivamos, neste trabalho, investigar se o segundo volume do livro didático de língua portuguesa de Ensino Médio Português vozes do mundo Literatura, Língua e Produção de Texto, dos autores Maria Tereza Arruda Campos, Lília Santos Abreu-Tardelli, Lucas Sanches Oda e Salete Toledo, dialoga com o que propõem teorias linguísticas de cunho sócio-discursivas, no que concerne ao tratamento com os gêneros. Para tanto, respaldamo-nos no aporte teórico-metodológico da Linguística Textual e em Bakhtin (2011) sobre o conceito de gênero. Os resultados apontam para a necessidade de se ter materiais didáticos mais condizentes com as propostas teóricas que fundamentam o ensino-aprendizagem de língua materna.
\end{abstract}

PALAVRAS-CHAVE: gêneros discursivos; língua portuguesa; livro didático.

ABSTRACT: Become consensus between linguists and teachers, after hard-fought discussions around school failure with regard to Portuguese teaching, that the basic teaching unit must be the text. Thus, the different discursive genres, oral or written, that organize and concretize our words, must give to the text functionality, since any linguistic manifestation that we produce is made through a genre. In this direction, it is necessary to prioritize a genre didactic transposition that facilitates the development of the apprentice social-discursive competence, making him/her able to linguistically actuate in a very wide range of communicative situations. Our aim, on this research, is to investigate whether the second volume of the high school Portuguese textbook Portuguese voices from the world - Literature, Language and Text Production, by Maria Tereza Arruda Campos, Lília Santos Abreu-Tardelli, Lucas Sanches Oda and Salete Toledo, engages with the linguistics theories postulates of a socio-discursive nature, concerning the genres treatment. Therefore, we are supported by Textual Linguistics theoretical-methodological framework and on Bakhtin (2011) about the genre concept. The results highlight the need of teaching materials more keeping with the theoretical proposals that native language teaching-learning is based.

KEYWORDS: discursive genres; Portuguese; textbook. 


\section{Revista do SELL}

v. 6 , no. 3

ISSN: $1983-3873$

\section{INTRODUÇÃO}

A todo instante somos convidados, implícita ou explicitamente, a nos posicionar em relação a algum assunto, reclamar o nosso direito, preencher requerimentos ou simplesmente ler um romance. É exatamente por meio da língua, independentemente da modalidade - oral ou escrita -, sob um texto materializado em algum gênero, que essas ações se tornam uma atividade possível.

Por meio da linguagem nos constituímos sujeitos capazes de atuar nas mais diversas práticas sociointeracionais, seja em situações mais práticas e corriqueiras, referentes às nossas necessidades imediatas de comunicação, seja em contextos mais formais, políticos e ideológicos, indicadores de que precisamos, na vida social, assumir determinadas posições. O primeiro caso - o uso da língua em situação mais prática - é garantido, via de regra, no contexto familiar imediato. Já no segundo - a língua que manifesta posicionamento político-ideológico - precisa-se mais do que o ambiente natural de aquisição da língua. Justamente aí, determina-se o papel da escola: ensinar usos não corriqueiros da língua (cf. MARCUSCHI, 2008).

Acreditamos que a principal protagonista nessa tarefa é a disciplina Língua Portuguesa. Não será com a inserção de demasiados conteúdos voltados para as regras gramaticais que se alcançará o objetivo - já previsto nos PCNs - de formar cidadãos críticos-reflexivos.

Quando começamos a frequentar os espaços formais de ensino, já temos um arcabouço linguístico oral bastante amplo, adquirido no seio familiar, com a devida inserção a um input linguístico, etc. Porém, quanto à produção de textos formais, esta precisa ser ensinada, mas esse ensino deve ser planejado e supervisionado, possibilitando ao aluno produzir textos eficazes nas mais variadas situações, de modo que suas produções se aproximem ao máximo do contexto real de uso e sejam comprometidas com a cidadania. Se o ensino de Língua Portuguesa é um evento relativamente recente, consequentemente, o ensino de produção textual o é ainda mais. As atividades voltadas para a gramática e para a leitura, por muito tempo, ocuparam o centro do ensino. Timidamente, as práticas de escrita apareciam na escola, mas o ensino formal e sistemático do escrever só começou a surgir por volta da década de 1960, fruto de reflexões acerca do ensino da Produção Textual. Todavia, segundo Bunzen (2006, p. 


\section{Revista do SELL}

v. 6 , no. 3

ISSN: $1983-3873$

144), "continuamos não encontrando um espaço dedicado ao ensino de produção escrita, pois o texto 'era tomado como objeto de uso, mas não de ensino-aprendizagem'".

Para aprender a escrever, é necessário ter acesso à diversidade de textos escritos, testemunhar a utilização da escrita em diferentes circunstâncias, defrontar-se com as reais questões que a escrita coloca a quem se propõe produzi-la, arriscar-se a fazer à sua maneira e receber ajuda de quem já é proficiente. Formar escreventes competentes supõe uma prática continuada de produção de textos em sala de aula, situações de produção de uma grande variedade de textos e uma aproximação das condições de produção às circunstâncias nas quais se produzem esses textos (SILVA. A; SILVA. L, 2013, p. 86).

Compreendemos que o professor da disciplina Língua Portuguesa possui uma atribuição ampla, que precisa contemplar os conteúdos gramaticais, literários e a produção textual ${ }^{1}$. As condições de ensino nem sempre são favoráveis, tendo em vista que, frequentemente, os professores reclamam da insuficiência de carga horária, falta de recursos didáticos complementares, entre outras questões; muitas vezes, o livro didático é o único material acessível para os professores e alunos, logo, a qualidade desse material, cuja importância é extrema nesse cenário, deveria ser, no mínimo, inquestionável.

Dada a importância que o livro didático assumiu no âmbito escolar, objetivamos investigar se o segundo volume do livro didático de língua portuguesa de Ensino Médio Português vozes do mundo - Literatura, Língua e Produção de Texto, dos autores Maria Tereza Arruda Campos, Lília Santos Abreu-Tardelli, Lucas Sanches Oda e Salete Toledo, adotado pela escola pública Centro Territorial de Educação Profissional (CETEP), de Vitória da Conquista - BA, dialoga com o que propõem as teorias linguísticas de cunho sociodiscursivos, no que concerne ao tratamento com os gêneros. Para alcançarmos nosso propósito, promovemos uma investigação quantitativa e qualitativa em tal livro. Assim, analisaremos, basicamente, três vertentes do material, quais sejam: a) a variedade de gêneros discursivos presente no livro; b) se os gêneros selecionados pelos autores proporcionam aos alunos sua compreensão e produção em situações sociocomunicativas reais de uso; c) no tocante à produção textual, se a proposta metodológica de trabalho com os gêneros considera as sequências didáticas recomendadas por Dolz, Noverraz e Schneuwly (2004).

\footnotetext{
${ }^{1}$ Essa divisão/fragmentação da disciplina é mais comum no Ensino Médio.
} 


\section{Revista do SELL}

v. 6 , no. 3

ISSN: $1983-3873$

\section{LÍNGUA, TEXTO E ENSINO À LUZ DOS GÊNEROS DISCURSIVOS}

Admitimos, em consonância com Antunes (2009), que a língua ultrapassa o conjunto de suas determinações internas e adquire um caráter político, histórico e sociocultural, logo, o ensino de línguas precisa absorver essas noções, cujas discussões têm sido realizadas de forma acalorada por linguistas, professores e educadores de diversos países. Conforme a autora, todas as questões que envolvem o uso da língua são de aspectos linguísticos e sociais, portanto, essas questões não podem ser resolvidas somente com base em livros de gramática ou sob o que preservam os manuais de redação.

O texto, por conseguinte, partindo do ponto de vista de que a língua é muito mais do que estrutura interna, é um evento sociointeracional, lugar de encontro e interação social; nas palavras de Koch (1997):

Poder-se-ia, assim, conceituar o texto, como uma manifestação verbal
constituída de elementos linguísticos selecionados e ordenados pelos
falantes durante a atividade verbal, de modo a permitir aos parceiros, na
interação, não apenas a depreensão de conteúdos semânticos, em
decorrência da ativação de processos e estratégias de ordem cognitiva,
como também a interação (ou atuação) de acordo com práticas
socioculturais (KOCH, 1997, p. 22 apud BENTES, 1999, p. 255).

Isto posto, percebemos que é na interação que o texto faz sentido e que sua manifestação só é possível por meio de um gênero discursivo/textual, uma vez que as nossas práticas socioculturais são discursivamente organizadas através dos gêneros. Já é trivial, portanto, o fato de que o ensino deve ocorrer fundamentado nos diversos gêneros. Fugir disso seria o mesmo que reduzir a língua à sua gramática interna, pois, quando enunciamos por meio de textos, orais ou escritos, a língua efetua-se com finalidades concretas, através de gêneros do discurso que são os "tipos relativamente estáveis de enunciados" (BAKHTIN, 2011, p. 261-262).

Nessa direção, são os gêneros do discurso/texto, primários e/ou secundários, que ordenam e estabilizam as nossas atividades comunicativas cotidianas. Eles apresentam características sociocomunicativas definidas pelo conteúdo, propriedade funcional, estilo e composição característica (cf. BAKHTIN, 2011; MARCUSCHI, 2007). Entretanto, não podem ser idealizados como um modelo rígido de classificação, pois, além de serem em número ilimitado (cf. MARCUSCHI, 2008), são definidos pelo meio de comunicação e por suas propriedades sociocomunicativas. 


\section{Revista do SELL}

v. 6 , no. 3

ISSN: $1983-3873$

Portanto, o surgimento dos gêneros está atrelado às necessidades imediatas que possuímos. Segundo Marcuschi (2007), eles surgem a partir de necessidades socioculturais das atividades humanas. É possível constatar essa afirmação se fizermos uma ligeira analogia, de um lado, com a época em que a escrita não fazia parte da sociedade e, de outro lado, com o momento contemporâneo. O último é marcado por um boom de novos gêneros, orais e escritos, sobretudo no que diz respeito aos meios eletrônicos, em geral, e à Internet, em particular, pois, como "práticas sociocomunicativas", os gêneros são dinâmicos e sofrem variações em sua constituição, que resulta, muitas vezes, em "novos gêneros" (KOCH; ELIAS, 2010). Em consonância com essa ideia, Antunes (2009, p. 55) sinaliza que:

[...] apesar de típicos e estáveis, os gêneros são também flexíveis; quer dizer, variam no decorrer de tempo, das situações, conforme a própria trajetória cultural diferenciada dos grupos em que acontecem. Variam ainda porque assumem novas formas, novas representações e valores; porque alteram sua frequência de ocorrência ou, ainda, porque surgem "novas caras", isto é, surgem gêneros novos.

Entretanto, frequentemente, a escola reporta-se aos gêneros apenas por suas características linguísticas. A essas características mais estritamente linguísticas dá-se o nome de sequências discursivas/tipologias textuais. Estas são em número limitado, cerca de meia dúzia ${ }^{2}$ - narração, descrição, argumentação, injunção e exposição (cf. MARCUSCHI, 2008) - e dizem respeito à predominância discursiva em cada gênero. O mesmo gênero, porém, pode apresentar várias sequências discursivas. A esse fenômeno, dá-se o nome de "heterogeneidade ${ }^{3}$ tipológica do gênero" (MARCUSCHI, 2007). No gênero carta argumentativa, por exemplo, é comum que apareçam o tipo argumentativo, o tipo expositivo e o tipo descritivo. Desse modo, os tipos textuais, caracterizam-se, a rigor, pela predominância de traços linguísticos, por isso, "um tipo textual é dado por um conjunto de traços que formam uma sequência e não um texto" (MARCUSCHI, 2007, p. 27).

Para efeito de ensino, podem ser utilizados uma variedade de gêneros. Alguns são viáveis apenas para conhecimento do aluno, mas não, necessariamente, para uma produção, devido a sua complexidade ou à série escolar em que será abordado, por exemplo. Decidir os gêneros que serão abordados no ambiente escolar requer do

\footnotetext{
2 Para uma abordagem mais detalhada acerca desses tipos textuais, conferir Marcuschi (2008, p.156-157), através de uma carta pessoal, o autor consegue contemplar todos os tipos textuais.

${ }^{3}$ Ainda sobre heterogeneidade e heterogeneidade funcional, conferir Bakhtin (2011, p. 262).
} 


\section{Revista do SELL}

v. 6 , no. 3

ISSN: $1983-3873$

professor discernimento e consciência da importância de um gênero em detrimento do outro para o desenvolvimento de práticas e habilidades sociocomunicativas dos estudantes. Do mesmo modo, a abordagem metodológica dos gêneros em sala de aula, isto é, sua didatização, requer planejamento prévio, sistematizado e sequenciado, procedimentos que são possibilitados por meio de sequências didáticas, as quais abordaremos na próxima seção.

\section{AS SEQUÊNCIAS DIDÁTICAS COMO PROCESSO METODOLÓGICO PARA O ENSINO DE LÍNGUA MATERNA}

Sabemos que o professor de língua portuguesa precisa abordar, em suas aulas, os conteúdos concernentes à estrutura da língua, à literatura e à produção de texto. Entretanto, algumas pesquisas já realizadas com o objetivo de compreender como o ensino de línguas tem sido realizado, como a de Lopes-Rosi (2011), por exemplo, apontam para um déficit nessa tríade, em que uma ou duas das vertentes deixam de ser priorizadas. Muitos motivos podem levar a isso: uma carga horária insuficiente para a realização das atividades planejadas, as concepções de língua e de textos que o professor possui, a limitação de materiais didáticos, entre outros fatores.

Lopes-Rossi (2011), na pesquisa mencionada acima, obteve resultados que assinalam duas dificuldades enfrentadas pelo professor de língua portuguesa, as quais impossibilitam uma prática mais reflexiva e coerente com os estudos contemporâneos. A primeira refere-se ao número reduzido de material de caracterização de gêneros aplicáveis ao ensino. A outra diz respeito à dificuldade de alterar/romper a prática pedagógica do ensino de produção de texto mantido pelo livro didático, que é, muitas vezes, o único recurso material comum ao professor e aluno, conforme já enfatizamos.

Sobre a questão dos livros didáticos, a autora faz uma analise rápida dos volumes $5,6,7$, e 8 da coleção didática de Fernandes e Hailer (2000). O resultado aponta para o fato de que a quantidade de gêneros que aparece no livro didático é muito grande, o que impede o desenvolvimento de um trabalho ancorado nas propostas dos PCN's. Nesse sentido, dificilmente um gênero é estudado em todos os seus aspectos. Conforme LopesRossi (2011, p. 80), "o contato dos alunos com o gênero em estudo é mínimo. São apresentados fragmentos de texto ou nenhum exemplo do gênero discursivo que o aluno deverá produzir em seguida". Em outras palavras, dificilmente um gênero é estudado em profundidade, desde o momento de sua compreensão ao momento de sua produção. 


\section{Revista do SELL}

v. 6 , no. 3

ISSN: $1983-3873$

Além disso, a didatização do gênero - a forma como ele é trabalhado na sala de aula ainda não permite a simulação de uma situação real de sua produção e, menos ainda, da circulação.

Geralmente, toda a proposta de produção é realizada em etapa única, sem refacção. As atividades são descontextualizadas e destituídas de sentido; os alunos precisam imaginar e inventar suas produções escritas a partir das suas próprias ideias (cf. LOPES-ROSSI, 2011). Nesse sentido, percebemos que o ensino de produção textual ainda precisa oferecer propostas de produção que levem os alunos a terem maior propriedade e proficiência naquilo que estão realizando.

O trabalho com os gêneros textuais, portanto, precisa ser realizado de maneira sistemática, para que os alunos possam compreender e se apropriar do gênero discursivo/textual cogitado, auxiliando-os no desenvolvimento de uma linguagem adequada à situação comunicativa e às finalidades do texto. Dolz e Schneuwly (2004) propõem que esse ensino deve ser empreendido por meio de um planejamento sequenciado e, para isso, criam as sequências didáticas.

Portanto, as sequências didáticas são "um conjunto de atividades escolares organizadas de maneira sistemática, em torno de um gênero textual oral ou escrito" (DOLZ; NOVERRAZ; SCHNEUWLY, 2004, p. 82). O objetivo imediato de se trabalhar sob a perspectiva das sequências didáticas é o de possibilitar meios mais fecundos para 0 ensino de produção textual, oral ou escrita, mesmo porque "não é de se supor que os alunos aprendam naturalmente a produzir os diversos gêneros escritos de uso diário. Nem é comum que se aprendam naturalmente os gêneros orais mais formais" (MARCUSCHI, 2007, p.36). Assim sendo, segundo Dolz, Noverraz e Schneuwly (2004), quatro etapas fundamentais devem ser cumpridas na estrutura básica das sequências, quais sejam: apresentação da situação; produção inicial; os módulos; produção final.

$\mathrm{Na}$ primeira etapa - apresentação da situação - procura-se descrever, detalhadamente, a intenção do projeto, inclusive deixar claro para os alunos a proposta de produção final. Nessa fase, apresenta-se um problema de comunicação bem definido (DOLZ; NOVERRAZ; SCHNEUWLY, 2004). É necessário expor os gêneros que serão abordados, a quem será dirigido, de que modo se dará e quem participará da produção.

A segunda etapa - momento de produção inicial - permite que o professor delineie um perfil inicial da turma, sua reação com a temática, recepção e/ou relutância. Nesse momento, os alunos precisam desenvolver alguma atividade, mesmo que para um 


\section{Revista do SELL}

v. 6 , no. 3

ISSN: $1983-3873$

destinatário fictício ou, apenas, para outros colegas da classe. Essa produção pressupõe um papel central como regulador da sequência didática, cujo objetivo é a realização de um diagnóstico que serve para os alunos se autoconhecerem e para o professor perceber o perfil da turma, de modo que possa realizar um trabalho baseado nas principais dificuldades encontradas (Cf. DOLZ; NOVERRAZ; SCHNEUWLY, 2004).

As oficinas posteriores, que fazem parte do terceiro momento das sequências didáticas, são distribuídas em quantos módulos forem necessárias, a depender do gênero, da temática etc. Elas serão (re)construídas a partir de um diagnóstico feito pelo professor, ou seja, a partir das dificuldades detectadas, sejam elas de ordem textual ou linguística. Logo, a orientação sugerida por Dolz, Noverraz e Schneuwly (2004) é a de que o professor possa estimular a capacidade necessária que o aluno deve ter para o domínio de um gênero. Assim, além de aprender a falar sobre os gêneros, os alunos adquirem, também, um vocabulário técnico, adequado a cada gênero.

Por último, a produção final é realizada com o objetivo principal de retomar a produção inicial, observando os progressos realizados, tecendo reflexões acerca do processo de produção - tanto por parte dos alunos quanto do professor. Há, nesse sentido, em relação aos alunos "um controle sobre seu próprio processo de aprendizagem" (DOLZ; NOVERRAZ; SCHNEUWLY, 2004, p. 90).

Notamos que as atividades propostas permitem uma funcionalidade maior, não apenas a de se obter uma nota no final da unidade, por meio de "prova escrita" ou da produção de um texto, que só o professor terá acesso, mas elas permitem, de alguma maneira, que os estudantes se sintam atraídos por verem seus produtos finais terem uma funcionalidade que atravessa as fronteiras de uma nota arbitrária. $O$ ideal é que o projeto seja realizado com temas que dialoguem com a realidade sociocultural da turma, algo que envolva e convide os alunos a pesquisarem durante todo o processo para que, por fim, apresentem possíveis sugestões e/ou soluções para o problema.

Reforçamos, então, a importância do desenvolvimento de um trabalho de ensinoaprendizagem de produção de textos que possa instituir como objeto de ensino os gêneros discursivos em todos os seus aspectos, com propostas que explorem todo o processo de compreensão e produção da forma mais autêntica possível, de modo que ultrapassem o universo escolar.

Na próxima seção, faremos uma breve, mas necessária abordagem sobre o livro didático, mostrando o momento em que ele passa a ser parte integrante do material 


\section{Revista do SELL}

v. 6 , no. 3

ISSN: $1983-3873$

utilizado na escola, para, então, observar o livro didático selecionado e investigar se suas propostas estão de acordo com as novas propostas de ensino-aprendizagem de língua materna que estamos discutindo, aqui.

\section{O LIVRO DIDÁTICO E O ENSINO DE LÍNGUA PORTUGUESA}

No Brasil, as primeiras aparições de materiais didáticos na escola se deram sob formas de cartilhas e manuais para o professor. Esses materiais, ao longo do tempo, vêm sofrendo diversas transformações, de "antologias, coletâneas de textos e gramáticas a um material único que abrigasse textos, gramáticas, exercícios e orientações" (SCHRÖDER, 2013, p. 206), as quais estão ligadas às conjunturas sociais, políticas e culturais em que ocorrem e "à evolução dos estudos linguísticos". O que fora feito, a priori, apenas como ferramenta norteadora para professores, passou a ser, também, o principal meio de pesquisa e fonte de atividades para os alunos. Portanto, o livro didático constitui-se, hoje,

Uma tradição tão forte dentro da educação brasileira que o seu acolhimento independe da vontade e das decisões dos professores. Sustentam essa tradição o olhar saudosista dos pais, a organização escolar como um todo, o marketing das editoras e o próprio imaginário que orienta as decisões pedagógicas do educador (SILVA, 1996, p. 10).

No que diz respeito ao livro didático de língua portuguesa, sua história está diretamente atrelada à história da constituição da disciplina. Precisamos considerar que a realidade escolar brasileira, até garantir a democratização do ensino, manteve a exclusão educacional por séculos. Tinham direito à educação apenas a classe dominante; aos demais, restavam o trabalho, a escravidão, a exclusão.

Conviviam, no Brasil, no período da colonização (entre os séculos XVI e XIX), pelo menos três línguas diferentes: o português, o latim e a língua geral. Esta última era a língua materna dos índios, que eram várias, mas, para que o processo de catequização obtivesse sucesso, os jesuítas precisavam conhecer essas línguas para uma comunicação comum entre eles e os nativos. Quanto ao latim, era a língua considerada clássica e, portanto, a mais prestigiada, sendo utilizada em espaços formais, como nas escolas, por exemplo; já o português, servia apenas de meio para um fim, isto é, por meio da gramatica do português se ensinava a gramática do latim. O português consolidou-se, no Brasil, graças ao intermédio do Marquês de Pombal, que implantou, por meio de suas 


\section{Revista do SELL}

v. 6 , no. 3

ISSN: $1983-3873$

reformas, um ordenamento jurídico e administrativo prescrevendo o uso obrigatório da língua portuguesa, inclusive em ambiente escolar (SCHRÖDER, 2013).

Até o século XIX, a língua portuguesa servia apenas de ferramenta para o ensino do latim, mas essa realidade começa a mudar em 1871, por meio de decreto imperial, através do qual é cunhado o cargo de 'professor de português' (SCHRÖDER, 2013), o que marca oficialmente $o$ início do ensino da língua portuguesa no Brasil.

A democratização na educação, a partir da década de 1950 do século XX, afetou diretamente o ensino-aprendizagem de língua portuguesa. Houve um aumento drástico de alunos, pois a classe trabalhadora passou a ter acesso à educação, e o número reduzido de profissional formado comprometeu a qualidade do ensino em diversas áreas. Quanto ao português, inicialmente os estudos eram voltados para a gramática, uma vez que o público escolar era constituído da classe econômica e socialmente privilegiada, a qual dominava a variante padrão e tinha, portanto, totais condições de estudar sobre a língua e fazer análise de textos literários canônicos. Nessa circunstância, "também o professor era usuário da norma padrão e era responsável pelo preparo de suas aulas pautadas em manuais para o ensino de gramática e em antologias para a exploração da literatura" (SCHRÖDER, 2013, p. 197).

Conforme Schröder, a ampliação do público-alvo escolar e a urgente necessidade de aumentar o corpo docente causou um déficit na formação desses novos profissionais, que, dessa vez, vinham, assim como os alunos, de classes mais populares e, portanto, não dominavam a variante padrão, como eram os professores anteriores a esta mudança. A formação oferecida, bem como o tempo e as condições do processo não favoreceram à qualidade e, segundo Schröder (2013), "no intuito de sanar esta necessidade escolar, foi realizado um recrutamento mais amplo e menos seletivo de professores" (SCHRÖDER, 2013, p. 197).

Até início do século $\mathrm{XX}$, o professor fazia uso de manuais didáticos apenas para deles extrair textos, antologias etc. A metodologia de trabalho a ser utilizada em sala de aula era definida de forma autônoma. Entretanto, a nova concepção de professor, advinda desse contexto de seleção "aleatória" de profissionais da educação, sobretudo a partir da década de 1970 do século XX, faz com que o estado opte pela modificação do material didático como solução imediata. Dessa forma, o livro didático ganha um novo sentido, ultrapassa a função de auxiliador, cujo objetivo era oferecer textos para o professor trabalhar à sua maneira, e passa a ser um orientador metodológico, trazendo propostas 


\section{Revista do SELL}

v. 6 , no. 3

ISSN: $1983-3873$

de atividades e até mesmo as sugestões de respostas (Cf. SCHRÖDER, 2013). Dito de outra forma, o livro didático passa a suprir a fragilidade na formação docente, uma vez que o tempo e a formação do professor estavam comprometidos. Consequentemente, conforme Schröder (2013, p. 198), "os livros didáticos surgem para suprir as lacunas de conhecimento desses professores, a ponto daqueles passarem a ser responsáveis pelas aulas destes". A partir de então, começa-se a diminuir a qualidade e mérito da função docente: há o aumento de sua carga horária e diminuição de sua remuneração, o que leva o professor a buscar no livro didático facilitação de sua tarefa.

O livro didático, de modo geral, e o livro didático de língua portuguesa, em particular, passam a ter um fim em si mesmos e a serem os colaboradores, direta ou indiretamente, pelo fracasso ou sucesso escolar. Entretanto, acreditamos que esta deva continuar sendo sim uma sugestão para o ensino-aprendizagem, funcionando como uma maneira de "padronizar e delimitar a matéria; apresentar métodos e processos julgados eficientes para o ensino e colocar ao alcance dos educandos e dos professores materiais necessários à objetivação do ensino" (SCHRÖDER, 2013, p. 199). Com isso, contrapomos a ideia, negativa e exagerada sobre o livro didático, defendida por Silva (1996), quando diz que esta é uma forma extremamente 'rasa', cujas possibilidades de movimento são impossibilitadas no âmbito do ensino-aprendizagem, e por isso é um material descartável e perecível, dado os meios modernos de circulação do conhecimento que temos. No entanto, compreendemos que o livro didático não pode ser 0 único material de consulta em sala de aula e que sua estrutura não é a mais desejável para este novo século, se levarmos em consideração a revolução tecnológica/eletrônica, mas até conseguirmos inserir os novos fenômenos conversacionais e um letramento digital em sala de aula (que, timidamente, vem adentrando o ambiente escolar), é a ele (livro didático) que muitos professores tem para recorrer, pois ainda é o material comum entre o educador e o educando para as suas consultas. E, por isso mesmo, por ser esse o material mais utilizado no dia a dia escolar, desde 1985 (para o Ensino Fundamental), e, desde 2007, (para o Ensino Médio), os livros didáticos passam a ser avaliados, antes de entrar na escola. O Plano Nacional do Livro Didático - PNLD (BRASIL, 2017) é o responsável por esta avaliação. Esse plano foi instituído pelo governo federal, oficialmente, por meio do Decreto $n^{\circ}$ 91.542. O órgão conta com uma junta de profissionais por área do conhecimento, que avalia e classifica o material como apto ou 


\section{Revista do SELL}

v. 6 , no. 3

ISSN: $1983-3873$

não para a escola, a partir de um montante de critérios. No caso do livro didático de língua portuguesa, sete vertentes são analisadas, quais sejam:

a natureza do material textual, as atividades de leitura e compreensão de textos escritos, as atividades de produção de textos escritos, as atividades propostas para a produção e compreensão de textos orais, as atividades de trabalho e reflexão sobre os conhecimentos lingüísticos [sic], o manual do professor, os aspectos gráfico-editoriais (ROJO; BATISTA, 2003, p. 307).

É também pelo fato de o livro didático de português fazer parte do cotidiano escolar que os conteúdos e a metodologia por ele adotados precisam estar de acordo com as novas propostas de ensino-aprendizagem de língua materna. Assim, com a intenção de realizar essa investigação, faremos, na seção seguinte, uma descrição do segundo volume do livro didático de língua portuguesa de Ensino Médio Português vozes do mundo - Literatura, Língua e Produção de Texto, dos autores Maria Tereza Arruda Campos, Lília Santos Abreu-Tardelli, Lucas Sanches Oda e Salete Toledo, a fim de verificar se há um diálogo com o que propõem as teorias linguísticas de cunho sociodiscursivo, no que concerne ao tratamento com os gêneros. A nossa análise será de cunho quantitativo e qualitativo.

\section{AS PÁGINAS DO LIVRO DIDÁTICO DE LÍNGUA PORTUGUESA SOB AS LENTES DOS GÊNEROS DISCURSIVOS}

Como expusemos na seção anterior, o livro didático passa por uma avaliação do PNLD, gerando um documento chamado "Guia do Livro Didático" (BRASIL, 2014). Neste documento, estão explícitos os critérios pelos quais os livros serão avaliados, bem como as resenhas das obras. O Guia do Livro Didático de Língua Portuguesa do Ensino Médio atual (2015 - 2017) conta com a avaliação de dez obras, dentre elas Português vozes do mundo - Literatura, Língua e Produção de Texto, corpus desta pesquisa.

A obra em questão é constituída de três partes, a saber: literatura, língua e produção de texto, respectivamente, assim distribuídas no sumário. Ressaltamos que essa divisão aponta para a fragmentação da disciplina, já criticada pelos PCNs de Língua Portuguesa (BRASIL, 1999). Interessa-nos, para fins desta pesquisa, a terceira parte produção de texto, que por sua vez é dividida em quatro unidades: narrar, relatar, expor e argumentar. Analisaremos, assim: a) a variedade de gêneros discursivos; b) se os 


\section{Revista do SELL}

v. 6 , no. 3

ISSN: $1983-3873$

gêneros selecionados pelos autores proporcionam aos alunos sua compressão e produção em situações sociocomunicativas reais de uso; e c) se a proposta metodológica de trabalho com os gêneros considera as sequências didáticas.

Nessa perspectiva, apresentamos, no quadro 1, a seguir, a variedade de gêneros discursivos/textuais encontrados no livro didático analisado, na seção de produção textual:

\section{a) Variedade de gêneros discursivos:}

Quadro 1 - Variedade de gêneros discursivos

\begin{tabular}{|l|l|}
\hline Gêneros discursivos/textuais & $\mathbf{N}^{\circ}$ de ocorrência \\
\hline História em quadrinhos & 1 \\
\hline Roteiro de peça de teatro (fragmento) & 1 \\
\hline Xilogravura & 1 \\
\hline Relato de viagem (trecho) & 3 \\
\hline Diário de viagem & 3 \\
\hline Crônica & 1 \\
\hline Artigo de divulgação científica & 3 \\
\hline Infográfico & 1 \\
\hline Relatório científico & 1 \\
\hline Transcrição de uma palestra na íntegra & 1 \\
\hline Transcrição de uma palestra (fragmento) & 1 \\
\hline Editorial de jornal & 2 \\
\hline Notícia & 1 \\
\hline Tabela & 1 \\
\hline Charge & 1 \\
\hline Transcrição de Debate (fragmento) & 1 \\
\hline Fórum & 1 \\
\hline Tirinha & 1 \\
\hline Propaganda & 2 \\
\hline Cartaz de campanha & 1 \\
\hline Trecho de artigo & 1 \\
\hline Poema & 1 \\
\hline
\end{tabular}

Fonte: Produzido pelas pesquisadoras com base no livro didático analisado.

No que concerne a essa parte, tendo em vista os objetivos das unidades e o limite de páginas (de 335 a 393), notamos, conforme mostra a tabulação no quadro1, que há um quantitativo amplo de gêneros. De modo global, se consideramos o histórico do ensino de língua portuguesa e a predominância de gêneros voltados para os textos canônicos da literatura portuguesa e brasileira, notamos que há um rompimento com essa tradição, assinalada pela presença de gêneros de outros domínios discursivos, tais como o jornalístico, científico, humorístico, etc. 


\section{Revista do SELL}

v. 6 , no. 3

ISSN: $1983-3873$

Apontamos para a extrema importância da diversidade textual em sala de aula, pois é no ambiente escolar, muitas vezes, que acontece o primeiro contato do aluno com determinados gêneros. É preciso, pois, apresentar e proporcionar ao educando as mais diversas situações de aparição dos gêneros, seus funcionamentos e adequações às circunstâncias sociocomunicativas. Entretanto, a ampla quantidade deles não implica na qualidade, nem no trabalho que dê conta de suas características, como veremos nas subseções a seguir.

\section{b) Os gêneros selecionados para compor as unidades proporcionam aos alunos sua compressão e produção em situações sociocomunicativas reais de uso?}

O guia do livro didático, em sua resenha sobre o eixo de produção de texto, afirma que esta acontece em "uma perspectiva de língua como atividade interativa, social e cognitiva, considerando as capacidades de linguagem do narrar, relatar, expor e argumentar" (BRASIL, 2014, p. 65). O eixo é subdividido em quatro unidades, sendo cada uma delas identificada por uma sequência discursiva e subdividida em capítulos.

A sequência discursiva intitula as unidades e todos os capítulos têm como objetivo contemplar essas sequências. Acreditamos, pois, que, ao colocar 0 tipo textual/sequências discursivas como o núcleo do ensino, faz-nos perder de vista que é o gênero do discurso que define as suas sequências narrativas e não o contrário. Nesse sentido, o ensino está sendo calcado nos tipos textuais, indo na contramão das orientações propostas pelos PCNs e pelas teorias linguísticas sobre ensino-aprendizagem de língua materna.

Devido ao espaço que temos para discussão, neste artigo, não há como fazer uma análise pormenorizada de todos os capítulos e, por isso, faremos, então, a descrição e análise de um capítulo, direcionado para o tipo textual "argumentar".

O capitulo 8, intitulado "A propaganda" traz, na seção "leitura do gênero", uma breve explicação dele, seguida da seguinte propaganda: 


\section{Revista do SELL}

v. 6 , no. 3

ISSN: $1983-3873$

Figura 1: Propaganda retirada do livro didático.

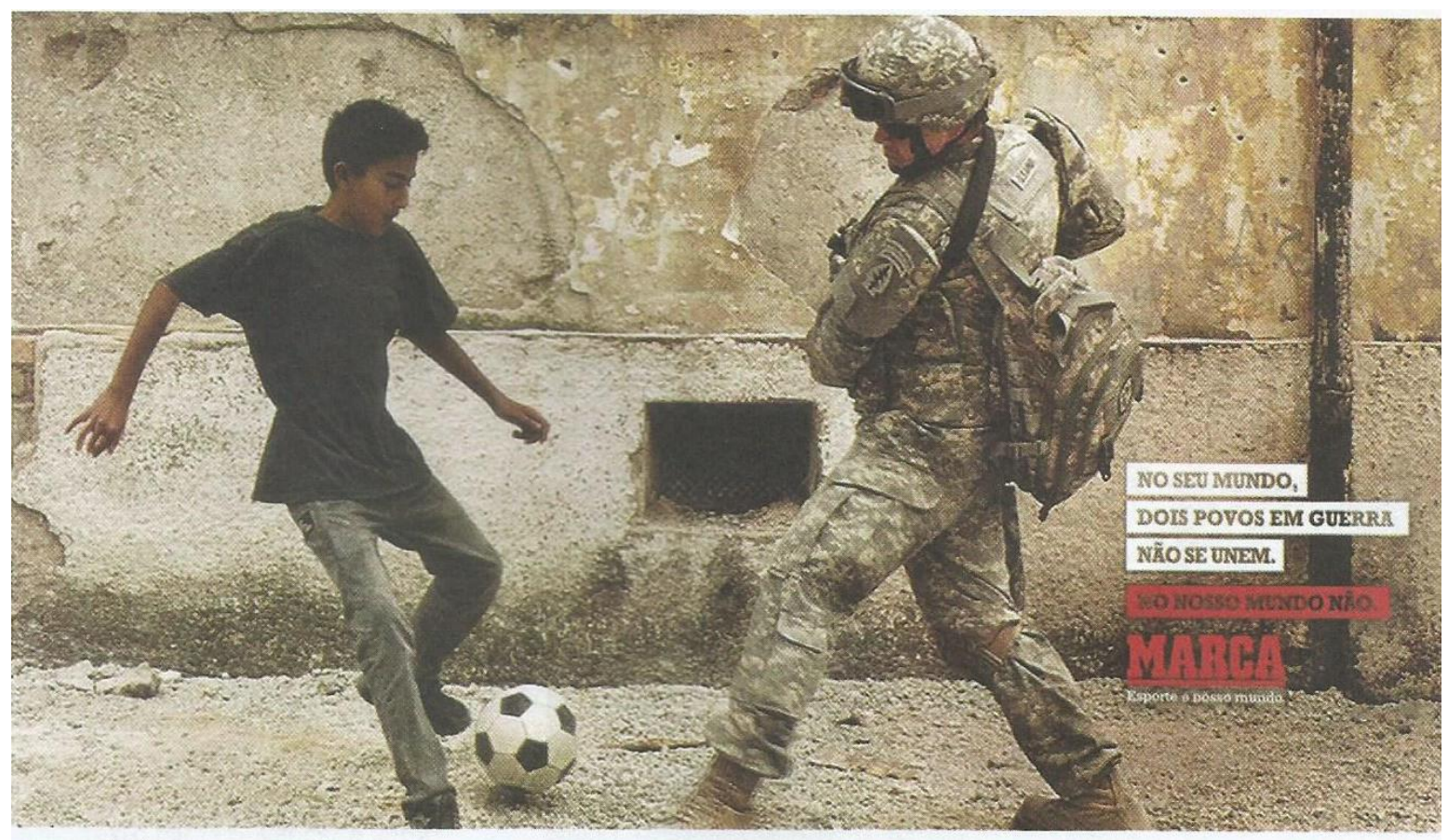

Iraque. Agência DM9DDB. Foto de Marcus Hausser. Disponivel em: <http://ccsp.com.br/novo/pop_pecas.php?id=37680>. Acesso em: 12 ago. 2012.

Fonte: Digitalizado pelas autoras do livro didático em análise.

Após a exposição da propaganda, os autores abrem uma seção de exercícios para tratarem do gênero. Os exercícios são intitulados da seguinte maneira: "contexto de produção", "os sentidos do texto", e "os elementos de composição".

Na seção denominada "contexto de produção", as questões são direcionadas para a produção da propaganda da figura 1, assim, aspectos do seu contexto de produção, seus objetivos, os possíveis leitores e as mídias em que o texto pode ser circulado são evidenciados. Em "os sentidos do texto", salientam-se as questões de sentido que dizem respeito aos protagonistas da cena enunciativa, seus papéis sociais, a representação do objeto "bola", os lugares sociais de quem fala e de quem lê e os sentidos de algumas palavras, como nosso, por exemplo. Por último, na seção que aborda "os elementos de composição", são destacados os mecanismos de persuasão da propaganda e a articulação da linguagem verbal e não verbal para a composição desse gênero.

As questões postas nos exercícios possibilitam a apreensão do gênero, as suas características formais, seu meio de circulação e suas funções sociocomunicativas, entretanto, a abordagem que fazem em cada uma das seções é superficial, não prepara, suficientemente, o aluno para uma posterior produção.

Outros gêneros, além da propaganda, entram em cena para discutir o ato de "convencer" e "persuadir", que são as principais funções sociocomunicativas do gênero 


\section{Revista do SELL}

v. 6 , no. 3

ISSN: $1983-3873$

em questão, quais sejam: um cartaz de campanha do IBAMA e um artigo científico (trecho). E, para finalizar o capítulo, é solicitada a seguinte proposta de produção:

Figura 2: Proposta de produção do gênero propaganda.

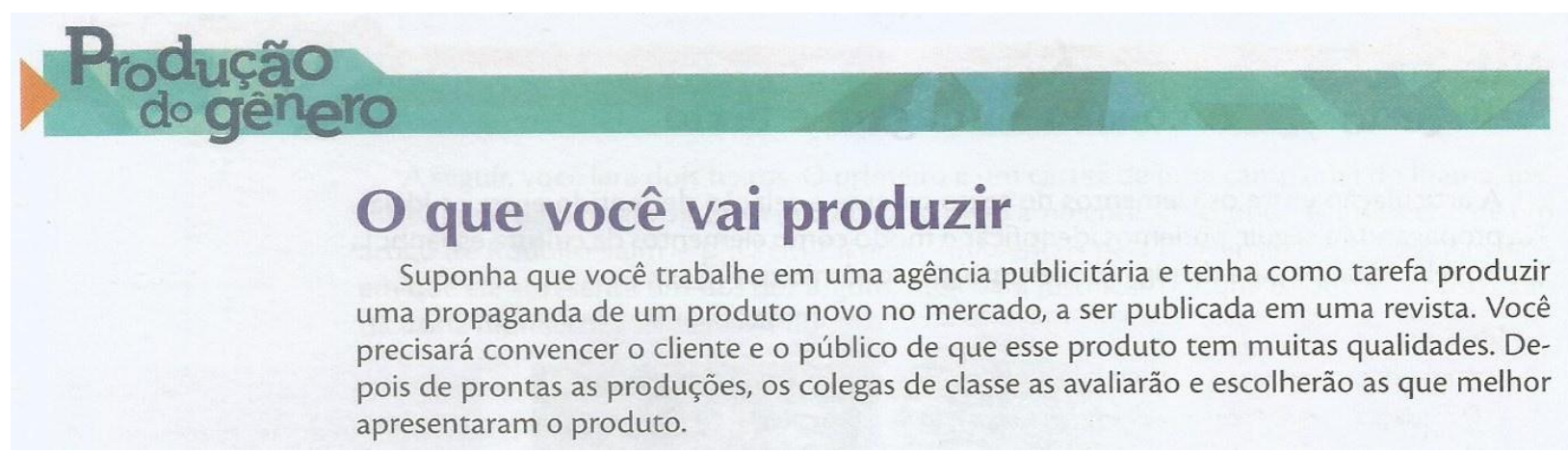

Fonte: Digitalizado pelas autoras do livro didático em análise.

É possível, pois, que o estudante compreenda o gênero trabalhado, mesmo porque são apresentados a ele vários textos, de vários gêneros que procuram argumentar, entretanto, atividades de produção como a proposta na figura 2 não consideram as condições de produção, os propósitos comunicativos e as características formais em que os gêneros são construídos e praticados. O aluno tem que supor uma situação sociocomunicativa para a produção do gênero, imaginar um contexto de circulação e o público a que será dirigido, o que afasta a produção de eventos sociocomunicativas reais de uso, pois, segundo Antunes (2005), a produção e a recepção de um texto devem ser "atividades interativas, de natureza sociocognitiva, uma vez que mobilizam conhecimentos de muitos tipos e são partes de atuações e práticas sociais mais amplas" (ANTUNES, 2005, p. 56).

Todos os capítulos do livro didático concernentes ao eixo de produção textual seguem a mesma lógica que descrevemos nesta seção, o que varia são as sequências discursivas e a seleção de gêneros para explorá-las.

\section{c) A proposta metodológica de trabalho com os gêneros considera as sequências didáticas?}

Quanto à metodologia utilizada pelo livro didático para o trabalho com os gêneros, consideramos que esta não segue a proposta dos autores Dolz, Noverraz e Schneuwly (2004), os quais recomenda que tal trabalho deva realizar-se de maneira sistemática, 


\section{Revista do SELL}

v. 6 , no. 3

ISSN: $1983-3873$

organizada e progressiva, por meio de sequências didáticas, para que os alunos possam compreender e se apropriar do gênero que está sendo trabalhado.

Deste modo, a proposta parece seguir, em termos de metodologia, uma etapa única. O que deveria ser a "apresentação da situação" é, na verdade, apresentação do tipo textual "argumentar" e, para isso, usa-se o gênero propaganda como meio de alcançar esse fim. Além disso, não identificamos o momento de produção inicial, muito menos o uso dela com objetivo de diagnosticar as dificuldades dos alunos para serem trabalhadas nas etapas posteriores, conforme propõem as sequências didáticas.

A terceira etapa de trabalho com o gênero também não é considerada, na qual terse-ia mais tempo para explorar os diversos aspectos do gênero, além de possibilitar a entrada em questões de ordem linguística e textual e retomar possíveis dificuldades encontradas na primeira etapa. A atividade de produção final fica restrita à sala de aula, isto é, não tem o propósito de dialogar com uma situação real, para fins sociais.

Observamos que as atividades são descontextualizadas e destituídas de sentido; na proposta de produção da figura 2, acima, por exemplo, os alunos precisam supor, imaginar e inventar suas produções escritas (cf. LOPES-ROSSI, 2011), o que torna virtual o processo de produção. Entretanto, consideramos positivo o fato de o livro didático propor a avaliação e a refacção da atividade, conforme mostra a figura 3:

Figura 3: Avaliação e reescrita

\section{Avalie e reescreva}

A classe pode ser dividida em grupos de quatro alunos. Os alunos de cada grupo apresentam sua propaganda uns para os outros. Os colegas devem fazer um comentário sobre cada produção avaliada. Os itens a seguir podem ajudar na avaliação.

\section{Público e suporte \\ A propaganda leva em consideração o público a quem é dirigido o produto e o suporte em que será publicada? \\ Coesão \\ A linguagem verbal e a não verbal estão articuladas de modo coeso? \\ Argumentos \\ Os argumentos são adequados para convencer o leitor a comprar o produto?}

Cada grupo seleciona a propaganda que considera mais adequada para vender os produtos. Um dos participantes justifica a escolha, apresentando os critérios que levaram os colegas a escolherem a propaganda.

Fonte: Digitalizado pelas autoras do livro didático em análise.

O processo de produção textual deve levar em conta a reescrita, quantas vezes forem necessárias. Conforme os PCN's, um texto é fruto de sucessivas versões, logo, sua 


\section{Revista do SELL}

v. 6 , no. 3

ISSN: $1983-3873$

refacção faz parte do processo de criação, por isso, o ensino-aprendizagem de gêneros precisa considerar o momento da produção e o momento da refacção (BRASIL, 1998), para que se obtenha efeitos positivos. Nesse sentido, percebemos que 0 ensino de produção textual, neste manual didático que selecionamos, em alguns aspectos, tem se aproximado das teorias concernentes ao ensino-aprendizagem de língua materna.

Consideramos, na seção anterior, que o livro didático é uma sugestão de trabalho para o professor. Cabe, portanto, ao docente, adequá-lo a uma metodologia viável, considerando a realidade e singularidade de seus alunos e as possibilidades de trabalho com o material disponível na escola, etc.

Em linhas gerais, o livro traz uma variedade de gêneros discursivos expressiva, conforme observamos no quadro 1 , todavia, a quantidade de gêneros não implica em condições favoráveis de produção, nem na qualidade que a abordagem é feita. Devido a essa quantidade e ao espaço físico do livro destinado à produção textual, relativamente curto, o tratamento com o gênero tornou-se superficial.

\section{Considerações finais}

Discutimos, nesse artigo, os liames entre as teorias linguísticas relativas ao ensino-aprendizagem de língua materna, na perspectiva dos gêneros discursivos/textuais, e sua aplicabilidade em sala de aula. Dada a importância do livro didático de língua portuguesa e o fato de este fazer parte do conjunto de políticas públicas para a educação brasileira, sendo, muitas vezes, o único material didático de que discentes e docentes possui no cotidiano escolar, quisemos investigar se o segundo volume do livro didático do ensino médio, intitulado Português vozes do mundo - Literatura, Língua e Produção de Texto trabalha o ensino de língua numa perspectiva sociointerativa, por isso o utilizamos como corpus desta pesquisa. Devido ao espaço que temos para discussão, analisamos apenas o eixo destinado à produção textual.

A obra analisada apresenta tanto fragilidades quanto pontos favoráveis ao ensinoaprendizagem de língua materna. No que diz respeito às fragilidades, nossas investigações mostram que o livro segue, ainda, a tradição de fragmentação da disciplina Língua Portuguesa, o que dificulta, ou mesmo impossibilita a interdisciplinaridade entre os conteúdos, como se gramática, literatura e produção de texto fossem três disciplinas antagônicas, sem qualquer afinidade entre si. 


\section{Revista do SELL}

v. 6 , no. 3

ISSN: $1983-3873$

Quanto ao tratamento dado ao gênero, as unidades referentes à produção de texto são reguladas pelas sequências discursivas e não pelo gênero, isto é, os gêneros discursivos são pretextos para o ensino dessas sequências, o que contradiz as teorias recentes sobre o ensino-aprendizagem de língua materna, que propõem um trabalho com textos pautado nos gêneros, pois, é por meio deles (e não da oração ou da palavra) que pode o sujeito se envolver nas práticas letradas cotidianas.

Além disso, as atividades propostas não seguem a metodologia proposta pelas sequências didáticas. Tomando como base as noções anteriormente apresentadas na subseção c, acima, o grupo de Genebra propõe que as práticas escolares sejam norteadas pelos chamados "modelos didáticos dos gêneros" a serem apropriados. Esse tipo de trabalho com base em um conjunto de atividades articuladas e planejadas com a intenção de atingir determinado objetivo didático inexiste no livro pesquisado. Sendo assim, não se prioriza as condições de produção, os propósitos comunicativos e as características formais em que os gêneros são construídos e praticados.

Embora a obra contenha fragilidades, apresenta, também, alguns avanços. Notamos uma considerável aparição na quantidade e diversidade de gêneros discursivos, bem como seu rompimento com a tradição apresentada pelos livros didáticos de língua portuguesa que vigorava até recentemente, nos quais, muitas vezes, só havia gêneros de domínios discursivos canonizados, como o literário, jornalístico, científico, etc. Além do mais, o livro indica a refacção das produções de textos, o que consideramos assertivo, pois, em consonância com as pesquisas nessa área, acreditamos que a produção de qualquer texto é, sempre, um processo, sendo assim, a refacção deve ser entendida como um procedimento natural.

Portanto, os resultados das análises apontam para a necessidade de se ter materiais didáticos ainda mais condizentes com as propostas teóricas que embasam o ensino-aprendizagem de língua materna, mas, também, assinalam para a proximidade que o livro didático de língua portuguesa vem impetrando com essas teorias. 


\section{Revista do SELL}

v. 6 , no. 3

ISSN: $1983-3873$

\section{REFERÊNCIAS}

ANTUNES, Irandé. Lutar com palavras: coesão e coerência. São Paulo: Parábola, 2005.

ANTUNES, Irandé. Língua, texto e ensino: outra escola possível. São Paulo: Parábola, 2009.

BAKHTIN, Mikhail. Estética da criação verbal. 6 ed. São Paulo: Martins Fontes, 2011.

BRASIL. Secretaria de Educação Fundamental, Parâmetros Curriculares Nacionais, terceiro e quarto ciclos do ensino fundamental: língua portuguesa. Brasília: MEC/SEF, 1998.

BRASIL. PCN - Parâmetros curriculares Nacionais. Ensino Médio: Linguagens, códigos e suas tecnologias. Brasília. MEC/SEF, 1999.

BRASIL. Guia de livros didáticos: PNLD 2015. Língua Portuguesa: ensino médio. Brasília: Ministério da Educação, Secretaria de Educação Básica, 2014.

BRASIL. Ministério da Educação. Plano Nacional do Livro Didático (PNLD). Disponível em:<http://portal.mec.gov.br/index.php?ltemid=668id=12391option=com_contentview=arti cle>. Acesso em: 24 abr. 2017.

BRONCKRART, Jean-Paul. Atividade de linguagem, textos e discursos: por um interacionismo sociodiscursivo. São Paulo: EDUC, 2009.

BUNZEN, Clecio. Da era da composição à era dos gêneros: o ensino de produção de texto no ensino médio. In: BUZEN, Clecio; MENDONÇA, Márcia (Orgs). ID. Português no ensino médio e formação do professor. São Paulo: Parábola, 2006, p. 139-161.

DOLZ, Joaquim; NOVERRAZ, Michele; SCHNEUWLY, Bernard. Sequências didáticas para o oral e a escrita: apresentação de um procedimento. In: SCHNEUWLY, Bernard; DOLZ, Joaquim. Gêneros orais e escritos na escola. Tradução de Roxane Rojo e Glaís Sales Cordeiro. Campinas, SP: Mercado das Letras, 2004, p. 81-108.

$\mathrm{KOCH}$, Ingedore Grunfeld Villaça. Linguística textual: retrospecto e perspectivas. São Paulo: Alfa, 1997.

$\mathrm{KOCH}$, Ingedore Grunfeld ; ELIAS, Vanda Maria. Ler e compreender: os sentidos do texto. São Paulo: Contexto, 2010.

LOPES-ROSSI, Maria Aparecida Garcia. Gêneros discursivos no ensino de leitura e produção de textos. In: KARWOSKI, Acir Mário; GAYDECZKA, Beatriz; BRITO, Karim Siebeneicher. (orgs.) ID. Gêneros textuais: reflexão e ensino. São Paulo: Parábola, 2011, p. 69-87.

MARCUSCHI, Luiz Antônio. Gêneros textuais: definição e funcionalidade. In: DIONISIO, Angela Paiva; MACHADO, Anna Rachel; BEZERRA, Maria Auxiliadora (Orgs.). ID. Gêneros textuais e ensino. Rio de Janeiro: Lucerna, 2007, p. $19-36$. 
MARCUSCHI, Luiz Antônio. Produção textual análise de gêneros e compreensão. São Paulo: Parábola, 2008.

ROJO, Roxane; BATISTA, Antônio Augusto (orgs.). Livro didático de língua portuguesa, letramento e cultura da escrita. Campinas, SP: Mercado de Letras, 2003.

SCHRÖDER, Mirian. $O$ ensino de língua portuguesa nas Páginas do livro didático. Revista Trama - Volume 9 - Número 18, 2013, p. 193 - 2008.

SILVA, Ezequiel Theodoro da. Livro didático: do ritual de passagem à ultrapassagem. Brasília: Em Aberto, ano 16, n.69, jan./mar. 1996, p. 10 -15.

SILVA, Auriane Menses Mesquita. SILVA, Lúcia Maria Leite da. Produção escrita assistemática, espontaneísta, improvisada, restrita às aulas de português. In: BORTONIRICARDO, Stella Maris. MACHADO, Veruska Ribeiro (orgs). ID. Os doze trabalhos de Hércules: do oral para o escrito. São Paulo: Parábola, 2013, p. 81-96. 